\title{
Adolescents Nutritional Association (Micronutrients) with Menarche: Role of Health Schemes and Services in India
}

SOMU NAIK ( $\sim$ somunaik535@gmail.com )

International Institute for Population Sciences

Aparna Jyothi Gangarapu

Tata Institute of Social Sciences

Shriya Bajaj

International Institute for Population Sciences

\section{Research Article}

Keywords: Adolescent health, Nutrition, Micronutrients, Menarche

Posted Date: December 30th, 2021

DOI: https://doi.org/10.21203/rs.3.rs-1070637/v1

License: (c) (i) This work is licensed under a Creative Commons Attribution 4.0 International License.

Read Full License 


\section{Abstract}

Menarcheal age in adolescent girls marks an important health concern in women's biology. The timing of menarche is an important determinant of Population size, Reproductive health and is an important factor of Health planning. The paper aimed to find the current mean age at menarche in India and its Nutritional association with micronutrients (given the role of government schemes and services). To fining out about the same the Menarcheal age group of (10-19 years) in India are examined. Binary logistic regression model is used to to estimate the association in the Menarcheal age among the Adolescent using the Comprehensive National Nutritional Survey. The mean age at menarche among adolescents stands at 9.07 years (95\% C.I.: 8.990,9.166), including the non menstruating girls within the concerned age group,the mean age was 12.815 years (95\% C.I.: 12.837,12.793). Girls with anemia are more likely to have their menarche 0.364 years higher than girls who are non amenic. The mean age at menarche is 0.72 years more likely to occur among those who have multivitamin tables/ syrup. The study concludes that over the time the age at menarche has declined rapidly with economic growth, urbanisation, Improvements in the Nutritional intake (addition of Micronutrients also seen a contributing factor). The area of concern with regard to Micronutrients supplementation is that, it is done so to provide proper nutritional factors but on the other hand is also causing early Mnearche that most of the Health scientists warned and seen it as a cause for ovarian, breat cancers and other diseases amongst girls in future. Hence its imprtant to keep a proper check on the dietary intake among girls at early stages of life.

\section{Background}

Menarcheal age in adolescent girls marks an important health concern in women's biology. It affects the reproductive health of a woman, other physical health problems, and mental health. A de cohort study revealed that early puberty is associated with increased risk of type 2 diabetes and Obesity, NHS cohort study revealed that young age at Menarche is associated with T2DM in adulthood (1).Multiple studies confirmed that early Menarche is a risk indicator for breast cancer. (2). It is not just a physical health concern but also affects socio-economic factors such as Education, Marriage, Early Motherhood, Early pregnancy, and other consequences. Determining age at menarche helps to detect all the possible health and socio-economic factors related to it in women. Women in India have been Regarded as the neglected sex in comparison to men. Gender discrimination plays a major role in terms of health with boys and men given nutritious food than girls. The health consciousness over women's health that has been improving day by day with various health schemes and health programs implemented like Janani Suraksha Yojana (2005), Indira Gandhi MatritvaSahi Sahyog Yojana (2010), Beti Bachao Beti Padao (2014), Rajiv Gandhi Scheme for Empowerment of Adolescent Girls (SABLA), school health programs, Weekly iron and folic acid supplementation, latest Ayushman Bharat Scheme 2018 focusing on Health services and Participation. The paper emphasizes the Role of Micronutrients in association with Menarche and the importance and relevance of the schemes available for Adolescent health in India.

Menarche is considered a milestone in women's reproductive life. (16). The timing of menarche is an important determinant of population size, reproductive health and is an important factor of health 
planning. (17). Menarche is affected by several factors including genetic, race, environmental, nutrition, geographical location, BMI, psychological factors, family size, socioeconomic status, physical stress, socioeconomic status, and more as cited in Tehrani, F.et al (2014) (16). The age at menarche demonstrated a secular declining trend over the past two centuries across the globe as pointed out by Tanner JM (1955) and others as cited in Pathak, Tripathi \& Subramanian (2014)(12).

In the 19th century factors that affected menarche particularly were climate, ethnic origin, social status, physical activity, education, sexual stimulation, housing, and health status; and 20th century documented other factors namely the birth, physique, family income, occupation, and education of parents, family size, etc, these new developments in the 20th century is observed due to the dramatic improvement of socioeconomic conditions, general health of the population in the industrialized countries that resulted in the early onset of puberty in children as argued by Karapanou \& Papadimitriou (2010)(11). Improvements in living standards, hygiene, nutrition, and healthcare, which are also considered to result in earlier sexual maturation in developing countries. (1).

Countries have been observing the declining trend in the age at Menarche owing to several factors. The mean age varied from 16.2 years in Nepal, 15.8 in Bangladesh, 12.38 in China, 13.5 in Sri Lanka; 12.8 in the US, 13.3 in Britain in developed countries. In India, the Nationally representative study was conducted last in 1972 which recorded mean age as 13.80 by the India council of medical research. Post-1972, several other states reported varied average ages at the Mean outcome of their respective state surveys. Delhi reported the average age at Mean in the Urban slum as 13.50, Uttar Pradesh reported mean age to be 12.43 among girls aged between 10-19 years. An All-India survey conducted by Pathank, Tripathi, Subramanian, (2014) reported the average age at Menarche of the Indian women population to be 13.62 where it was 13.76 years in 2005.(12). A very recent study conducted in Goa witnessed young girls reaching menarche at an early age of 8 and 9 years compared to 12-14 years decades ago. (3)

Nutrition as an important lifestyle factor, in the timing of puberty, has been acknowledged increasingly. (1). High growth diet leads to growth hormones kicking in soon starting Menarche. (TOI, 2014, para.2). "Micronutrients play an important role in the proper growth and development of the human body and its deficiencies affects the health contributing to low productivity and a vicious cycle of malnutrition" (Toteja, 2014). Micronutrients help in the health and development of children and adolescents during their time of growth. Micronutrient deficiency is an important cause of morbidity and mortality, especially in infants and preschool children. The microenvironment deficiency in children and adolescents includes Iron, iodine, vitamin A and Zinc. (MoHFW, 2019). Goyal, Mehta \& Kaur (2017) found out through their study conducted in Punjab to find out the Nutritional status and Menarche in Adolescents of Punjab reveals that menarche is delayed due to undernutrition and as the Nutrition improves, the attainment of menarche is lowered.(13)

Several studies conducted before this research tried to find out the Association of Micronutrients with Puberty in girls have marked significant results in other countries excluding India. Villamor and Jansen, (2016) states the Role of iron, zinc, and other micronutrients in reproductive functioning and offering 
development and estimates the status of these nutrients during childhood may be related to the timing of sexual maturation(22). Further points out about the evolutionary theory that predicts the deficiencies in the nutrients could be related to the delayed onset of sexual maturation on the other hand children having sufficient nutrients earlier in life would develop it sooner. Citing the results of various researches in funding the association of Micronutrients reveal:

- Intake of calcium, magnesium, and phosphorus by girls in the upper median in Iran showed higher odds of experiencing menarche before 12 years of age compared to others.

- Swiss girls supplemented with calcium from ages 7.9-8.9 reached menarche earlier than the placebo group.

- A positive association between iron intake and age at menarche among 230 girls from the US is observed.

- Vitamin A intake was strongly associated with earlier menarche in a study conducted by Maclure.

Studies on Micronutrients reported the intake of Vitamin A, B12, C, and thiamine were related to earlier age at Menarche; Vitamin C intake showed a positive association with Menarche among girls of 10-13 years of age group in Quebec City area as cited in Liu, (2017) (8). Dietary intake of Zinc was associated with earlier menarche in Girls in Britain among 3298 British girls who participated in ALSPAC. (18). One other study conducted in Columbia assessing the status of Micronutrients in middle childhood with their association at an age at menarche revealed that the association of ferritin was stronger in girls aged 9-10 years and HB concentration in middle childhood resulted in early menarche and is opposite in the case of ferritin. (23). Two prospective observational studies in girls have reported a delayed menarcheal age with its association of higher fiber intakes in childhood (1).

The prevalence of Anaemia is more than $60 \%$ among adolescent girls a study indicates that examined the Prevalence of Anaemia among pregnant women and Adolescent girls. (20). The results revealed that the overall prevalence of Anaemia in adolescent girls was $90.1 \%$, with $7.1 \%$ of the population being severely Anemic. Union government. The Comprehensive National Nutritional Survey 2016-2018 survey reveals Female adolescents have a high prevalence of Anemia at $40 \%$ than in males having $18 \%$. The survey indicates that Anaemia has decreased steadily over time with an increase in the household wealth in all three age groups (0-5 years) Preschool, (5-14years) school-going/early adolescents, (15-19 years). Anemia has remained a major health issue in India decades for now and continues to be until today. Iron deficiency being the most important cause of Anaemia, pregnant women, infants, and adolescents are highly affected by the same. (Ministry of Health and Family Welfare (MoHFW), Government of India, UNICEF and Population Council,2019). Other factors that lead to Anaemia are also due to lack of other micronutrients Vitamin A, Vitamin B12, Folate, and other illnesses. (MoHFW, Government of India, UNICEF and Population Council,2019)

\section{Health schemes and programs in India}


Several programs and schemes implemented in India aimed at improving the nutritional and health status of the population, via Integrated Child Development Services, Mid-day Meals program, National iodine deficiency disorders control program, National Iron Plus initiative, and yet a large portion of the population still suffers from Malnutrition and micronutrient deficiency. The Ministry of Women and Child development, Government of India in 2000 launched Kishor Shakti Yojana to improve the nutritional and health status of girls belonging to the 11-18 age group in various Health-related aspects and awareness of Personal Hygiene, Nutrition, overall development, etc. Nutritional program for Adolescent girls was initiated in 2002-2003 targeting the undernourished adolescent girls provided free food grains per beneficiaries in targeted 51 districts. (Ministry of Women and Child Development, Government of India, 2010)

MoWCD later came up with an Umbrella scheme for Adolescent girls replacing KSY and NPAG targeting the nutrition of the 11-19 age group population. The Rajiv Gandhi Scheme for Empowerment of Adolescent Girls (RGSEAG) / SABLA implemented various initiatives through the ICDS platform and dissemination of the scheme via AWC's.(9)

The iron supplementation scheme so far improved the status of Anaemia, reducing $16 \%$ from $74.3 \%$ among preschool children during 1998-1999 to 58.5\% during 2015-2016. In 2013, weekly iron and folic acid supplementation were launched subsequently to reduce Nutritional Anaemia among adolescents covering the age group of 6 months to women of reproductive age. (4).

With the iron supplementations programs, successfully the rate of Anaemia has come down but surprisingly risks of other micronutrient deficiencies detected caught attention. Gonmei \& Toteja (2018) (4) shows a recent study conducted in Telangana among women aged 15-35years lower prevalence of Anaemia to be $28.4 \%$, other hand prevalence of other micronutrient deficiencies reported as $46.3 \%$ ferritin deficiency, folate to be $56.8 \%$, Vitamin B12 to be $44 \%$, etc. which shows the need for policies and schemes to also direct the provisions to reduce other micronutrient deficiencies.

The existing literature suggests that there is an association of Micronutrients and Menarche proved by studies taken place in different countries but in India, since micronutrient supplementation to adolescent girls had begun only in 2013 in India, an all India pooled research related to micronutrition and its association with menarche has not been studded yet, whereas this was not the case with other countries like Korea, US, Mexico unlike in India, the micronutrient supplementation programs had begun in late 19th century. The strength of the current research study is assessing the role of micronutrients concerning Menarche for the Indian adolescent population belonging to the age group 10-19. The age group marks important criteria for the study since 10-19 represents the younger population and recent developments can be observed, $15-45$ or other age groups that capture all menstruating women do not yield beer results for the study since it coincides with the generational gap and a wide range of factors like Influence of Marriage and other socio-economic factors.

\section{Methods}


The cross-sectional data for the present study comes from the Comprehensive National Nutritional Survey (2016-18) which was conducted under the Ministry of Health and Family Welfare (MoHFW), Government of India in collaboration with the United Nations Children's Fund (UNICEF). The CNNS is nationally representative of a multi-stage survey which is also considered as the largest micronutrient survey where 11,2316 children and adolescents were interviewed and 51,029 blood and stool samples were drawn across 30 states and union territories. 35,830 Out of the total 112,316 are from 10-19 age groups. It provides various dimensions of nutrition including Anemia and hemoglobinopathies, Inflammatory biomarkers, Protein, Micronutrients, Non-communicable diseases, and socio-economic and demographic dimensions as well. The survey questionnaire was translated into 20 state-specific Indian languages and administered through trained local field interviewers.

The CNNS asked all the girls in-between the age group 10-19, 'At what age have you had your first menstrual period?' during the face-to-face interview with the presence of a parent or guardian. Out of a total 35,830 respondents, about 23,510 girls $(66 \%)$ have yet to get their menarche. Hence the final analytical sample was reduced to 12,320 girls between the ages 10-19.

Outcome variable: for the present study, the age at which the subject has got her first period is considered as a dependent variable as the questionnaire has asked to report about the age at menarche.

Exposure variables: In this study, a set of demographics, socioeconomic, micronutrient as well as anemia has been used for analysis. The mean age of menarche has been calculated for two groups. Since our data set consists of 10-19 adolescent girls, many girls have not got their period till the date of the interview.

The socio-economic characteristics of children and adolescence are counted through caste, religion, and wealth quintile of their parents and the demographic characteristics by the place of residence, state.. For adolescent girls: the haemoglobin levels $<11.5 \mathrm{~g} / \mathrm{dl}$ ( any anaemia), World Health Organization, 2011. For iron deficiency: if serum ferritin $<15 \mu \mathrm{g} / \mathrm{l}$;all CPR $>5 \mathrm{mg} / \mathrm{L}$ were excluded, Geneva, WHO, 2011.(26). For vitamin A,Serum retinol concentration $<20 \mu \mathrm{g} / \mathrm{dl}$; all cases with CRP $>5 \mathrm{mg} / \mathrm{L}$ were excluded, World Health Organisation, 2009.(25) For vitamin-D, Serum 25(OH)D concentration $<12 \mathrm{ng} / \mathrm{mL}(30 \mathrm{nmol} / \mathrm{L})$, Institute of Medicine (IOM), 2011. For zinc, Serum zinc concentration $<70 \mu \mathrm{g} / \mathrm{dl}$ (morning fasting) and < $66 \mu \mathrm{g} / \mathrm{dl}$ (morning non-fasting) in non-pregnant females and $<74 \mu \mathrm{g} / \mathrm{dl}$ (morning fasting) and $<70 \mu \mathrm{g} / \mathrm{dl}$, International Zinc Nutrition Consultative Group, 2012. For vitamin-B12, Serum vitamin B12 level $<203$ $\mathrm{pg} / \mathrm{ml}$, World Health Organisation, 2008. For folate, Serum erythrocyte folate level $<151 \mathrm{ng} / \mathrm{ml}$, World Health Organisation, 2008. For lodine(suboptimal) urinary iodine concentration $<50 \mu \mathrm{g} / \mathrm{L}$, WHO/UNICEF/ICCIDD, 2007(27).

We used bivariate analysis to present the age at menarche for different regions and salient socioeconomic, demographic, anemia, and micronutrients among girl children during the study period. We have used One-way analysis of variance (ANOVA) to test the statistical differences in age at menarche across different risk factors. To find the possible association between anemia, and micronutrients, we have categorized our dependent variable into dichotomous. By using logistic 
regression model because the dependent variable is dichotomous (Menarche: 1 for who have attended or 0 for who have not yet attended) in nature, the following model has been used:

Yi Binom(pi)

$Y i=\ln$

$=\beta 0+\beta 1 X 1+\beta 2 X 2 \ldots \ldots \ldots+\beta n X n$

Where () is the odds ratio and

$\beta 0$ is representing the intercept term of the model,

$\beta i$ (where $i=1,2, \ldots n)$ is the coefficient of ith variable and

$X i$ (where $i=1,2, \ldots n$ ) is with anemia and micronutrients.

The above model is used for the bivariate logistic regression and multivariate logistic regression.

\section{Results}

Table No. 1: Mean age at menarche (including and excluding those who did not get their puberty) with respect to background characteristic 


\begin{tabular}{|c|c|c|}
\hline $\begin{array}{l}\text { Background } \\
\text { characteristics }\end{array}$ & $\begin{array}{l}\text { Mean age at menarche (including those } \\
\text { who did not get menarche yet) }\end{array}$ & $\begin{array}{l}\text { Mean age at menarche (excluding those } \\
\text { who did not get menarche yet) }\end{array}$ \\
\hline India & 9.078 & 12.815 \\
\hline \multicolumn{3}{|l|}{ Residence } \\
\hline Rural & 8.864 & 12.936 \\
\hline Urban & 9.336 & 12.679 \\
\hline \multicolumn{3}{|l|}{ Caste } \\
\hline SC & 9.135 & 12.827 \\
\hline ST & 8.926 & 12.837 \\
\hline $\mathrm{OBC}$ & 8.801 & 12.577 \\
\hline Others & 8.707 & 12.637 \\
\hline \multicolumn{3}{|l|}{ Religion } \\
\hline Hindu & 9.080 & 12.838 \\
\hline Muslim & 9.194 & 12.797 \\
\hline Christian & 8.902 & 12.734 \\
\hline Sikh & 9.249 & 13.021 \\
\hline Others & 9.141 & 12.608 \\
\hline \multicolumn{3}{|l|}{ Wealth index } \\
\hline Poorest & 8.050 & 12.967 \\
\hline Poor & 8.628 & 12.949 \\
\hline Middle & 8.857 & 12.916 \\
\hline Rich & 9.235 & 12.856 \\
\hline Richest & 9.517 & 12.655 \\
\hline
\end{tabular}

Table no. 1 shows the mean age at menarche of India. As we have considered the adolescent age group, we have girls who did not get their period at the time of survey. The mean age of menarche including girls who did not get their period is 9.078 Mean \pm 0.044 S.E. but in case of exclusion we have the mean of $12.815 \pm .0114$ S.E.

Considering the place of resident, the mean age is higher in urban in the inclusion of those who did not get menarche but in case of exclusion, rural people are showing higher results. In case of caste, 'SC' showing the higher result for the former one and in the later one 'other' showing the higher value. For 
religion 'Sikh' is showing higher value in both the cases. In wealth index, 'poorest' shows the lowest value in former one and 'richest' shows the lower value in later one.

The result regarding the geographical region reflects variation in the contribution of mean age at menarche for both including and excluding girls who did not get their period at the time of survey. In case of inclusion Jammu and Kashmir got the highest and Nagaland got the lowest age at menarche. Exclusion shows that Gujarat has the highest value and Assam has the lowest age at menarche.

Table No. 2: Mean age at menarche with respect to Micronutrients 


\begin{tabular}{|c|c|c|}
\hline Micronutrients & $\begin{array}{l}\text { Mean age at menarche (without exclusion } \\
\text { of those did not get yet) }\end{array}$ & $\begin{array}{l}\text { Mean age at menarche (exclusion of } \\
\text { those did not get yet) }\end{array}$ \\
\hline \multicolumn{3}{|l|}{$\begin{array}{l}\text { Folate } \\
\text { Deficiency }\end{array}$} \\
\hline Without & 8.954 & 12.711 \\
\hline With & 8.865 & 12.860 \\
\hline \multicolumn{3}{|l|}{$\begin{array}{l}\text { lodine } \\
\text { Deficiency }\end{array}$} \\
\hline Without & 8.828 & 12.796 \\
\hline With & 9.255 & 12.921 \\
\hline \multicolumn{3}{|l|}{$\begin{array}{l}\text { Vitamin B12 } \\
\text { Deficiency }\end{array}$} \\
\hline Without & 8.714 & 12.725 \\
\hline With & 9.772 & 12.972 \\
\hline \multicolumn{3}{|l|}{$\begin{array}{l}\text { Vitamin A } \\
\text { Deficiency }\end{array}$} \\
\hline Without & 8.881 & 12.873 \\
\hline With & 9.083 & 12.635 \\
\hline \multicolumn{3}{|l|}{$\begin{array}{l}\text { Vitamin D } \\
\text { Deficiency }\end{array}$} \\
\hline Without & 8.811 & 12.812 \\
\hline With & 9.137 & 12.750 \\
\hline \multicolumn{3}{|l|}{$\begin{array}{l}\text { Zinc } \\
\text { Deficiency }\end{array}$} \\
\hline Without & 8.896 & 12.792 \\
\hline With & 9.393 & 12.787 \\
\hline \multicolumn{3}{|l|}{$\begin{array}{l}\text { Iron } \\
\text { Deficiency }\end{array}$} \\
\hline Without & 8.080 & 12.772 \\
\hline With & 10.740 & 12.812 \\
\hline \multicolumn{3}{|l|}{$\begin{array}{l}\text { Presence of } \\
\text { Anaemia }\end{array}$} \\
\hline No & 8.350 & 12.807 \\
\hline
\end{tabular}




\begin{tabular}{|lll|}
\hline Micronutrients & $\begin{array}{l}\text { Mean age at menarche (without exclusion } \\
\text { of those did not get yet) }\end{array}$ & $\begin{array}{l}\text { Mean age at menarche (exclusion of } \\
\text { those did not get yet) }\end{array}$ \\
\hline Yes & 9.862 & 12.808 \\
\hline
\end{tabular}

Table no. 2 states that the mean age of menarche with respect to different micronutrient have been calculated for both the cases. Interestingly in the former case people with iron deficiency have the highest mean age which is 10.740 while people without iron deficiency have the lowest mean age at menarche. In the later case, the micronutrient shows very less variation.

Table No. 3: Odds ratio of mean age at menarche with respect to micronutrients 


\begin{tabular}{|c|c|c|c|}
\hline Micronutrients & Odds Ratio & \multicolumn{2}{|c|}{ [95\% Conf.] } \\
\hline \multicolumn{4}{|l|}{ Folate Deficiency } \\
\hline With ${ }^{\circledR}$ & 0.000 & 0.000 & 0.000 \\
\hline Without & $0.894^{*}$ & 0.796 & 1.003 \\
\hline \multicolumn{4}{|l|}{ Iodine Deficiency } \\
\hline With ${ }^{\circledR}$ & 0.000 & 0.000 & 0.000 \\
\hline Without & $0.731^{*}$ & 0.565 & 0.945 \\
\hline \multicolumn{4}{|c|}{ Vitamin B12 Deficiency } \\
\hline With ${ }^{\circledR}$ & 0.000 & 0.000 & 0.000 \\
\hline Without & 1.104 & 0.974 & 1.252 \\
\hline \multicolumn{4}{|l|}{ Vitamin A Deficiency } \\
\hline With ${ }^{\circledR}$ & 0.000 & 0.000 & 0.000 \\
\hline Without & 0.909 & 0.81 & 1.019 \\
\hline \multicolumn{4}{|l|}{ Vitamin D Deficiency } \\
\hline With ${ }^{\circledR}$ & 0.000 & 0.000 & 0.000 \\
\hline Without & $0.459 * \star \star$ & 0.4098 & 0.514 \\
\hline \multicolumn{4}{|l|}{ Zinc Deficiency } \\
\hline With $®$ & 0.000 & 0.000 & 0.000 \\
\hline Without & $0.882^{\star \star \star}$ & 0.788 & 0.987 \\
\hline \multicolumn{4}{|l|}{ Iron Deficiency } \\
\hline With ${ }^{\circledR}$ & 0.000 & 0.000 & 0.000 \\
\hline Without & $0.332^{\star \star \star}$ & 0.293 & 0.376 \\
\hline \multicolumn{4}{|c|}{ Presence of Anaemia } \\
\hline Yes ${ }^{\circledR}$ & 0.000 & 0.000 & 0.000 \\
\hline No & $0.364^{\star \star \star}$ & 0.324 & 0.41 \\
\hline Adjusted R square & 0.116 & & \\
\hline No. of observation & 7034 & & \\
\hline
\end{tabular}

Table no.3 shows the significance among the micronutrients and the mean age at menarche. Girls with anaemia are more likely to have their menarche 0.364 years higher than those girls who don't have 
anaemia. Zinc deficient plays a highly significant role in menarche. Girls without iron deficiency are likely to have 0.668 years less than those who have iron deficiency.

Table No. 4: Mean age at menarche with respect to government initiative

\begin{tabular}{|lcc|}
\hline Micronutrients & $\begin{array}{l}\text { Mean age at menarche(inclusion of } \\
\text { those did not get yet) }\end{array}$ & $\begin{array}{l}\text { Mean age at menarche( exclusion of } \\
\text { those did not get yet) }\end{array}$ \\
\hline $\begin{array}{l}\text { Consumption of } \\
\text { multivitamin }\end{array}$ & \\
\hline yes & 8.37 & 12.76 \\
\hline no & 9.18 & 12.82 \\
\hline don't know & 7.39 & 12.89 \\
\hline Iron and folic suppliment & \\
\hline yes & 8.38 & 12.75 \\
\hline no & 9.18 & 12.82 \\
\hline dont know & 6.30 & 12.75 \\
\hline Awareness of govt schemes & \\
\hline yes & 10.95 & 12.94 \\
\hline no & 8.88 & 12.94 \\
\hline don't know & 8.26 & 12.74 \\
\hline Usage of govt schemes & \\
\hline yes & 11.34 & 13.01 \\
\hline no & 10.30 & 12.81 \\
\hline
\end{tabular}

Table no. 4 reflects that in both cases, the mean age at menarche is greater for those who did not consume multivitamin as compare to those consume. The mean age at menarche has been found to be 8.3 years in case of Consumption of iron and folic supplement with the inclusion and 12.7 years in case of exclusion.

Table No. 5: odds ratio with respect to different government initiative 


\begin{tabular}{|llll|}
\hline Regression with respect to menarche & odds ratio & C.I. & \\
\hline Consumption of multivitamin & & & \\
\hline yes ${ }^{\circledR}$ & 0.00 & 0.00 & 0.00 \\
\hline no & $0.28^{\star \star}$ & 0.05 & 0.50 \\
\hline Iron and folic supplement & & & \\
yes ${ }^{\circledR}$ & & & \\
\hline no & $0.12^{\star *}$ & -0.08 & 0.32 \\
\hline don't know & $1.08^{\star *}$ & -1.11 & 3.26 \\
\hline Usage of govt schemes & & & \\
\hline yes ${ }^{\circledR}$ & 0.00 & 0.00 & 0.00 \\
\hline no & $-1.10^{\star * \star}$ & -1.26 & -0.94 \\
\hline
\end{tabular}

Table no. 5 states that the government initiative has been found a good association for the mean age at menarche. The mean age at menarche is 0.72 years more likely to occur those who have multivitamin tables/ syrup. Similarly, people with iron and folic supplement are 0.87 years more likely to have their mean age at menarche. Interesting the awareness of the government schemes and initiative has been found collinear. But the usage of government schemes is found to be highly significant.

\section{Discussion}

There are some limitations that need to be considered while interpreting the results. The present study gives the cross-sectional nature of the data, we could not identify any causal relationship between outcome and exposure variables. Rather, we only identify the association between the micronutrients and presence of anaemia with the menarche age of adolescent girls.

The study is based on the retrospective or recall method for the measurement of menarche age. There are some studies which criticize the recall method for over-reporting the menarche age, while certain studies have accused it of under-reporting the menarche age. Some have compared recall data with other sources of information and noted that the recall method provides fairly consistent estimates.

Sampling and sample size was designed to present results at the state level. The analysis below the state level will not be statistically representative. Disaggregated analysis, at the state level, cannot be done due to limitations in sample size. Therefore, we suggest that further studies take up the longitudinal surveys to evaluate the present scenario and identify the casual risk factors of menarche age among adolescent girls and adolescent pregnant girls and also to conduct a comparative study in pre-menarche and postmenarche nutrition. 


\section{Conclusion}

The study concludes that over time the age at menarche has declined rapidly with economic growth, urbanization, Improvements in the Nutritional intake and others. The current mean at menarche stands at 8.2 years for India, which is an alarming factor for future health consequences of adolescent health and other social implications. The study also found that there is a significant association of micronutrients and menarche, with girls who are anemic tend to have menarche at 0.36 years later to the non -anemic girls. The government schemes did play a major role in adolescent health in terms of improved nutrition and micronutrient deficiencies where adolescents who are supplemented with idol and folic acid consumption noticed early age at menarche with a mean age at. 8.3 and 12.7 otherwise.

The area of concern here in the case of Micronutrients is that adolescents provided with multivitamins in addition to the dietary regime are seeing early age at recharge and vice versa. Multivitamin supplementation is implemented in the first place to improve vitamin deficiency but probably because the adolescents are supplemented with more than enough nutrients, the hormones might be kicking in soon causing menarche. Hence, the micronutrients supplementation should be closely Monitored and adolescent health should be the major priority in detecting early Brest cancer symptoms and other possible diseases since girls with early menarche are more prone to health problems. Early menarche is also closely with early marriages, and early reproductive signs, hence, more health and other schemes should target these issues for adolescents for their physical, mental and other issues.

More studies in the field of science to cater to the preventive measures for possible health risks of adolescents to be conducted. More studies are needed in order to predict which girls may develop metabolic or psychological disturbances due to early menarche and whether they can be benefited by medical manipulation of the pubertal events. (Karapano \& Papadimitriou, (2010)).

\section{Policy Implications}

"Malnutrition in India, particularly among women, children, and adolescents is an emergency needing immediate attention if the country has to have inclusive growth and development". (5). The adolescent population constitutes nearly $16.75 \%$ of the total female population which is approx. 8.3 crores. $56.2 \%$ of women belonging to the age category (15-49) are Anemic and this was largely due to the lack of targeted health schemes and services for adolescents, widespread gender discrimination in their access to health services, early age at marriage putting the adolescent health at much danger. Kishore Shakti Yojana was the first scheme launched for adolescents in 2000 by the Ministry of women and child development, Govt of India to improve the nutritional status of the age group 11-18 years, under which 2-3 Adolescent girls are targeted per AWC provided with supplementary nutrition. Nutritional Programme for Adolescent girls was initiated later on in 51 targeted districts providing $6 \mathrm{~kg}$ of free good grains per beneficiary for the underweight girls. An umbrella scheme replacing KSY and NPAG was introduced in 200 selected districts, the Rajiv Gandhi Scheme for Empowerment of Adolescent Girls. (MoWCD, GOI,2010) 
The new scheme focused on the overall development of the Adolescents in addition the Micronutrients supplementation began. Under the scheme, each AG is given supplementary nutrition of 600 calories, 1820 grams of protein, and micronutrients. National nutritional Anaemia control program includes the schoolgirls (6-10 years) and adolescents of (11-18) years under the National Rural Health Mission have been included. The review of the scheme revealed that the scheme adhered to the Adolescent girl's Anemia control program. (14). A study was conducted to understand the efficacy not Twice Weekly Iron Supplementation in Anaemic Adolescent Girls by Shoba, S \& Sharada. (2003) among 244 subjects revealed that the Haemoglobin level increased steadily in all subjects who are supplemented with iron and folic tablets and as the supplementation period increased. The Programmes have been successful, one of the studies reviewed the SABLA scheme in Bikaner dist. revealed that $73.5 \%$ of the girls reported that they are aware of the Adolescent Girl's scheme while $26.5 \%$ reported that they were not aware, majority of the respondents are aware of the welfare schemes yet do not have knowledge on how to avail those benefits. Although awareness is present, the functioning of the scheme noticed certain backdrops, the problem of irregular supply of food of $12 \%$, irregular supply of drugs $12 \%$. A study conducted by Joshi, M \& Gumashta, R. 2013 (6) assessing the weekly iron folate supplementation in Adolescent girls reveals that the overall prevalence of Anemia was brought down by $25 \%$ in the 'Daily Iron Folic Acid Supplementation' group after the supplementation for nearly 3 months while it was brought down by $31.67 \%$ in the group provided with weekly supplementation.

\section{Declarations}

\section{Ethics approval and consent to participate (Not Applicable)}

Consent for publication (Not Applicable)

Availability of data and materials: The datasets generated and/or analysed during the current study is publically available only on request.

Funding (Not applicable)

Authors' contribution: Aparna and I wrote the main manuscript text. Shriya edited the manuscript. I participated in the data analysis. All the authors reviewed the manuscript.

Acknowledgement:- I would like to thank the reviewes of the paper for their valuable suggestions in the paper.

\section{Author Information}

\section{Affiliations}

International Institute for Population Science, Mumbai

Somu Naik 


\section{Tata Institute of Social Science, Hyderabaad}

Aparna Jyothi Gangarapu

\section{International Institute for Population Science, Mumbai}

Shriya Bajaj

\section{Corresponding Author}

Correspondence to Somu Naik

\section{References}

1. Cheng et.al (2010) Beyond Overweight: nutrition as an important lifestyle factor influencing timing of puberty Nutrition Reviews p. 133-149, doi:10.1111/j.1753-4887.2011. 00461.x

2. de Waard F, Trichopoulos D. A unifying concept of the aetiology of breast cancer. Int J Cancer. 1988 May 15;41(5):666-9. doi: 10.1002/ijc.2910410505. PMID: 3366487.

3. Girl Talk- Menarche now at 8-9 years (2015) Times of India.

https://timesofindia.indiatimes.com/city/goa/girl-talk-menarche-now-at-8-9years/articleshow/34169175.cms

4. Gonmei, Z., \& Toteja, G. S. (2018). Micronutrient status of Indian population. The Indian journal of medical research, 148(5), 511-521. https://doi.org/10.4103/ijmr.IJMR_1768_18

5. Indian National Science Academy (2011), Micro-Nutrient Security for India-Priorities for Research and Action.

6. Joshi, M., \& Gumashta, R. (2013). Weekly iron folate supplementation in adolescent girls--an effective nutritional measure for the management of iron deficiency anaemia. Global journal of health science, 5(3), 188-194. https://doi.org/10.5539/gjhs.v5n3p188

7. Khatoon, T.,Kumari,R.,Rupani,R.,Verma, A. (2011) Age at menarche and affecting bio-social factors among the girls of Lucknow,Uttarpradesh Research Gate, 33,03, p.221-223

8. Liu,Y (2017). A Study of the Impact of Environmental Chemicals and Micronutrients on Pubertal Development in A Mexican Population, University of Michigan ORCID iD: 0000-0002-2979-9552

9. Ministry of Women and Child Development, Government of India (2010) Rajiv Gandhi Scheme for Empowerment of Adolescent Girls (RGSEAG)-- 'SABLA' - The scheme.

10. Ministry of Health and Family Welfare (MoHFW), Government of India, UNICEF and Population Council. (2019). Comprehensive National Nutrition Survey (CNNS) National Report. New Delhi.

11. Karapanou, O., Papadimitriou, A. Determinants of menarche. Reprod Biol Endocrinol 8, 115 (2010). https://doi.org/10.1186/1477-7827-8-115

12. Pathak, P. K., Tripathi, N., \& Subramanian, S. V. (2014). Secular trends in Menarcheal age in Indiaevidence from the Indian human development survey. PloS one, 9(11), e111027. 
https://doi.org/10.1371/journal.pone.0111027

13. Rajni Goyal, Promila Mehta \& Ginjinder Kaur (2012) Nutritional Status and Menarche in Adolescents of Punjab, Journal of Life Sciences, 4:1, 63-66, DOI:10.1080/09751270.2012.11885197

14. Rajpurohit,D., Nareen,S., Tyagi,S. Meena,M. \& Rajvi,J. (2019) Constraints faced by beneficiaries of 'SABLA' scheme for adolescent girls (11-18 years) in Bikaner district: A review International Journal of Home Science P. 356-389

15. Rajpurohit,D., Nareen,S., Tyagi,S. Meena,M. \& Rajvi,J. (2019) Advantages of 'SABLA' scheme for adolescent girls (11-18 years) in Bikaner district: A review International Journal of Home Science p. 360-363

16. Ramezani Tehrani, F., Mirmiran, P., Gholami, R., Moslehi, N., \& Azizi, F. (2014). Factors influencing menarcheal age: results from the cohort of tehran lipid and glucose study. International journal of endocrinology and metabolism, 12(3), e16130. https://doi.org/10.5812/ijem.16130

17. Rah JH, Shamim AA, Arju UT, Labrique AB, Rashid M, Christian P. Age of onset, nutritional determinants, and seasonal variations in menarche in rural Bangladesh. $J$ Health Popul Nutr. 2009;27(6):802-7.

18. Rogers IS, Northstone K, Dunger DB, Cooper AR, Ness AR, Emmett PM. 2010. Diet throughout childhood and age at menarche in a contemporary cohort of british girls. Public Health Nutr 13:2052-2063.

19. Singh. (2018) Women Health in India: Issues and Schemes International Journal of Research and Analytical Reviews,5,4 p.82-86.

20. Toteja,G.S.(2006). Prevalence of Anemia in Pregnant women and adolescent girls in 16 districts in India 27(4):311-5. https://pubmed.ncbi.nIm.nih.gov/17209473/

21. Eun Jeong Yu MD,Seung-Ah Choe MD ,Jae-Won Yun MD 3, Mia Son MD(2019). Association of Early Menarche with Adolescant Health in the setting of Rapidly Decreasing Age at Menarche North American Society for Paediatric and Adolescent Gynaecology p.264-270 https://creativecommons.org/licenses/by-nc-nd/4.0/

22. Villamor, E., Jansen, E. (2016). Nutritional Determinants of the Timing of Puberty. Annual Rev. Public Health,10.1146/annurev-publhealth-031914-122606,p. 33-46.

23. Villamor, E., Marin, C., Mora-Plazas,M., Oliveros, H.,(2017) Micronutrient status in middle childhood and age at menarche: results from the Bogotá School Children Cohort British Journal of Nutrition p.1097-1105, doi:10.1017/S0007114517003130

24. Wei, Liu, Cheng, Yang, Zhu, Zenfg.(2014). Association of Infant Physical Development and Rapid Growth with Pubertal Onset Among Girls in Rural China JAMA Network Open,p. 1-13, doi:10.1001/jamanetworkopen.2021.6831

25. WHO 2009a World Health Organization. Vitamin and Mineral Nutrition Information System (VMNIS): Micronutrients database, 2009. http://www.who.int/vmnis/database/en/ accessed April 18, 2014.

26. WHO 2011b World Health Organization (2011), Serum ferritin concentration for the assessment of iron status and iron deficiency in population, Geneva, WHO, 2011. 
27. WHO 2007b. Growth References 5-19 years (accessed on 12 September 2017). Retrieved from https://www. who.int/growthref/who2007_bmi_for_age/en/ 